\title{
Hypoxic preconditioning protects photoreceptors against light damage independently of hypoxia inducible transcription factors in rods
}

Brigitte Kast ${ }^{1}$, Christian Schori ${ }^{1,2}$, Christian Grimm ${ }^{1,2,3}$

${ }^{1}$ Lab for Retinal Cell Biology, Department of Ophthalmology, University of Zürich, Zürich, Switzerland

${ }^{2}$ Center for integrative human physiology (ZIHP), University of Zürich, Zürich, Switzerland

${ }^{3}$ Neuroscience Center (ZNZ), University of Zürich, Zürich 8057, Switzerland.

Corresponding author:

Christian Grimm

Lab for Retinal Cell Biology

Department Ophthalmology

University of Zürich

Wagistrasse 14

CH 8952 Schlieren, Switzerland

Email: cgrimm@opht.uzh.ch

Tel: 0041445563001 


\section{Abstract}

Hypoxic preconditioning protects photoreceptors against light-induced degeneration preserving retinal morphology and function. Although hypoxia inducible transcription factors 1 and 2 (HIF1, HIF2) are the main regulators of the hypoxic response, photoreceptor protection does not depend on HIF1 in rods. Here we used rod-specific Hif2a single and Hif1a;Hif2a double knockout mice to investigate the potential involvement of HIF2 in rods for protection after hypoxic preconditioning. To identify potential HIF2 target genes in rods we determined the retinal transcriptome of hypoxic control and rod-specific Hif2a knockouts by RNA sequencing. We show that rods do not need HIF2 for hypoxia-induced increased survival after light exposure. The transcriptomic analysis revealed a number of genes that are potentially regulated by HIF2 in rods; among those were Htra1, Timp3 and Hmox1, candidates that are interesting due to their connection to human degenerative diseases of the retina. We conclude that neither HIF1 nor HIF2 are required in photoreceptors for protection by hypoxic preconditioning. We hypothesize that HIF transcription factors may be needed in other cells to produce protective factors acting in a paracrine fashion on photoreceptor cells. Alternatively, hypoxic preconditioning induces a rod-intrinsic response that is independent of HIF transcription factors.

\section{Keywords}

Hypoxia-inducible factors, HIF, retinal degeneration, hypoxic preconditioning, neuroprotection, light damage, photoreceptors 


\section{Introduction}

Retinal degenerative diseases lead to severe visual impairment and blindness. Several approaches such as gene therapy, retinal prosthesis, cell transplantation, optogenetics or neuroprotection are researched with the goal to establish effective treatment options for patients suffering from inherited or acquired retinal degenerations. To identify molecular mechanisms of disease development and progression, and to provide proof of principle for future therapies, various inherited and induced animal models have been developed that mimic human retinal degenerations in many aspects (Samardzija et al., 2010; Fletcher et al., 2011; Samardzija \& Grimm, 2014). Among those, exposure of rodents to high levels of visible light has gained much attention and is frequently used to induce synchronous photoreceptor death in order to investigate activity of specific factors, to identify novel mechanisms and signaling pathways and to test neuroprotective approaches (Wenzel et al., 2005; Grimm \& Remé, 2013).

Hypoxic preconditioning is one of the most effective treatments preventing the retina from degeneration by a subsequent insult. Erythropoietin (EPO) produced during hypoxic conditions has been identified as a factor that may be part of this protection (Grimm et al., 2002). During hypoxic preconditioning, hypoxia-inducible transcription factors (HIF1 and HIF2) are activated to regulate expression of a myriad of common and specific target genes involved in many aspects of cell metabolism. HIF transcription factors are composed of an oxygen-regulated alpha and a constitutively expressed beta subunit. The alpha subunits of HIF1 and HIF2 (HIF1A and HIF2A) are constantly produced but destabilized in normoxic conditions through hydroxylation of two proline residues by $\mathrm{O}_{2}$-dependent prolyl hydroxylases (PHDs). Hydroxylized HIFA subunits are recognized by the Von Hippel Lindau (VHL) protein complex containing an E3 ligase that polyubiquitinates HIFA proteins targeting them for fast proteasomal degradation. In an environment with reduced oxygen availability, PHDs lack their co-substrate $\left(\mathrm{O}_{2}\right)$ and thus do not hydroxylate HIFA proteins. Consequently, HIFA proteins are not ubiquitinated and thus escape degradation. Instead, HIFA subunits translocate to the nucleus, interact with HIFB and act as transcription factor (Caprara \& Grimm, 2012; Greer et al., 2012; Ratcliffe, 2013). This system is active in most cells of the body to react almost instantaneously to a reduction of the oxygen concentration in the tissue. The HIF system is also present in the retina and is strongly activated under hypoxic conditions. Since photoreceptors have an exceptionally high need for energy (Okawa et al., 2008), they are thought to experience borderline hypoxic conditions especially during night time when oxygen demand is highest (Yu \& Cringle, 2001; de Gooyer et al., 2006). An oxygen sensing system may thus allow photoreceptors to quickly adjust their metabolism according to oxygen concentration in the tissue and therefore contribute to survival in changing conditions. It has been hypothesized for example, that 
photoreceptors in the old eye are supplied with less oxygen due to reduced choroidal blood flow and impaired oxygen diffusion through the aged ocular tissue with alterations such as a thickened Bruch's membrane, altered retinal pigment epithelium (RPE) containing increased levels of lipofuscin, and a larger number of Drusen in the sub-RPE space (Arjamaa et al., 2009; Kent, 2014). Stabilization of HIFA proteins and activation of HIF1 and HIF2 transcription factors may thus support photoreceptors in such suboptimal conditions. In chronic hypoxia however, constant activation of the HIF pathway may also contribute to disease development through increased expression of HIF target genes such as vascular endothelial growth factor (VEGF), or by shifting energy production from mitochondrial respiration to glycolysis effectively reducing ATP production.

Although hypoxic preconditioning has been shown to protect retinal ganglion cells in a model of glaucoma (Zhu et al., 2013) or ischemic damage (Whitlock et al., 2005; Zhu et al., 2007), and photoreceptors against light-induced degeneration (Grimm et al., 2002), the detailed mechanisms behind the protection have not been described. Nevertheless, several molecules have been identified that contribute to protection. Delta-opioid receptor was reported to participate in hypoxia-induced retinal protection after elevation of intraocular pressure (Peng et al., 2009). Heat shock protein 27 (Hsp27) (Whitlock et al., 2005) and heme oxygenase 1 (Hmox1) (Zhu et al., 2007) may play a role in the elevated tolerance to ischemia by hypoxic preconditioning, and Epo has been shown to protect retinal cells including photoreceptors, ganglion cells and RPE against degeneration in a variety of models (Grimm et al., 2002; Junk et al., 2002; Grimm et al., 2004; Rex et al., 2009; Wang et al., 2009; Colella et al., 2011; Chang et al., 2013; Gu et al., 2014; Shen et al., 2014). Although these factors were shown to be induced by hypoxia in the retina, the contribution of HIF transcription factors remains unclear, most likely because of the variety of models used and the potential of HIFs to act in trans by producing secreted factors that protect cells in a paracrine fashion. In a previous study we have shown that photoreceptors do not need intrinsic HIF1 for surviving light exposure after hypoxic preconditioning but did not address the role of HIF2 in this paradigm (Thiersch et al., 2009). Since HIF1 and HIF2 regulate hypoxic expression of common but also of specific target genes and show some cell type specificity (Loboda et al., 2012; Zhao et al., 2015), we now focused on HIF2 and analyzed the potential contribution of rod specific HIF2 to protection by hypoxic preconditioning. 


\section{Material and methods}

\subsection{Mice.}

Animal experimentation was performed in compliance with the guidelines of the Veterinary Office Zurich and the declaration of "The Association for Research in Vision and Ophthalmology" for the use of animals in research. All mice were kept in a light-dark cycle of $12: 12 \mathrm{~h}$ with an average light intensity of about 60 lux at cage level.

Rod specific knockouts of Hif2a (Rod $\left.{ }^{\Delta \text { Hif2a }}\right)$ and Hif1a;Hif2a (Rod $\left.{ }^{\Delta H i f a ; \Delta H i f 2 a}\right)$ mice were generated by appropriate breeding schemes using mice that carry loxP sites on either side of exon 2 of the Epas1 (Hif2a) gene (Gruber et al., 2007), mice that carry loxP sites on either side of exon 2 of Hif1a (Ryan et al., 2000) and LMOPC1 mice that express CRErecombinase under control of the rhodopsin promoter (Le et al., 2006). Although LMOPC1 mice express CRE specifically in rods, expression is patchy and detectable in roughly $50 \%$ to $70 \%$ of rod photoreceptors (Le et al., 2006; Lange et al., 2011). Genotypes were determined by conventional PCR using genomic DNA isolated from ear biopsies and specific primer pairs (Table 1).

CRE mediated excision of floxed DNA sequences was detected on genomic DNA isolated from retinal tissue using conventional PCR and appropriate primer pairs (Table 1). Since excision was specific for rod photoreceptors and genomic DNA was isolated from all retinal cells, the excised $(1-l o x P)$ as well as the unexcised $(2-l o x P)$ sequences were amplified. As expression of CRE recombinase starts at around PND7 and increases gradually up to the age of 6 weeks (Le et al., 2006), all mice were at least 10-12 weeks old at the time of experiment. All mice used were homozygous for the leucine variant in RPE65 (Rpe65 ${ }^{450 L e u}$ ), which renders mice more susceptible to light damage (Wenzel et al., 2001).

Data shown were derived from 3 to 11 mice. Individual $N$ values are given in figure legends for each experimental condition and genotype. $N$ values represent the number of mice used; only one eye per mouse was used for a particular experimental approach.

\subsection{Hypoxic preconditioning and light exposure.}

Mice were placed in a hypoxic chamber with food and water ad libitum, and were gradually accustomed to hypoxic conditions by decreasing the oxygen concentration (by altering the $\mathrm{O}_{2}: \mathrm{N}_{2}$ ratio) every 10 minutes by $2 \%$ starting with $19 \% \mathrm{O}_{2}$ at 8.00 am and ending with $7 \% \mathrm{O}_{2}$ at 9.00 am. Hypoxic preconditioning lasted for 6 hours at $7 \% \mathrm{O}_{2}$. After preconditioning, mice were transferred to normal room air in darkness for $4 \mathrm{~h}$, followed by an exposure to $15^{\prime} 000$ lux of white light for $2 \mathrm{~h}(7 \mathrm{pm}-9 \mathrm{pm})$. Pupils were dilated $40 \mathrm{~min}$ prior to light exposure with one drop of $1 \%$ cyclogyl (Alcon, Cham, Switzerland) and one drop of $5 \%$ phenylephrine (Ciba Vision, Niederwangen, Switzerland). After light exposure, 
mice were returned to darkness until next morning when they were returned to the normal 12:12 $\mathrm{h}$ light-dark cycle until euthanasia by an overdose of $\mathrm{CO}_{2}$ followed by cervical dislocation. Mice that were exposed to light without hypoxic preconditioning were treated equally, with the exception that animals were kept in normal room air at all times.

\subsection{Morphology.}

Eyes were enucleated and immediately submerged in $0.1 \mathrm{M}$ cacodylate buffer $(\mathrm{pH}$ 7.3) containing $2.5 \%$ glutaraldehyde. After overnight fixation at $4{ }^{\circ} \mathrm{C}$, cornea and lens were removed and the eyecup bisected along the nasal-temporal axis through the optic nerve head. After washing in cacodylate buffer, the tissue was washed twice in phosphate buffered saline (PBS) for $15 \mathrm{~min}$, incubated in $1 \%$ osmium tetroxide for $1 \mathrm{~h}$, dehydrated in increasing ethanol concentrations and embedded in Epon812. Semi-thin sections of $0.5 \mu \mathrm{m}$ were cut and counterstained with toluidine blue for light microscopy (Axioplan 2; Carl Zeiss AG, Feldbach, Switzerland).

\subsection{Electroretinography (ERG).}

ERGs were recorded essentially as described (Seeliger et al., 2001) using an LKC UTAS-E 3000 recording unit (LKC Technologies, Inc. Gaithersburg, MD, USA). After dark adaptation over night, pupils were dilated and anesthesia was induced by a subcutaneous injection of a mixture of ketamin $(66.7 \mathrm{mg} / \mathrm{kg}$ ) and rompun (xylazine, $11.7 \mathrm{mg} / \mathrm{kg}$ ). Recording gold electrodes were placed directly onto the cornea, a reference electrode was inserted under the skin between the eyes and a grounding electrode was positioned subcutaneously at tail base. Mice were placed in a Ganzfeld chamber and scotopic responses to single white-flashes (ranging from -3.7 to $1.9 \log \mathrm{cd}^{*} \mathrm{~s} / \mathrm{m}^{2}$ ) were recorded from one eye. For photopic ERG, mice were light adapted for $5 \mathrm{~min}$ and stimulated with single flashes (-0.6 to $2.9 \log \mathrm{cd}^{*} \mathrm{~s} / \mathrm{m}^{2}$ ) with background lights on. Ten responses per flash intensity were averaged, and amplitudes determined and blotted as a function of light intensity. Recordings shown in Figure 3B were done using a new LKC UTAS Bigshot ERG recording unit (LKC Technologies, Inc.) with flash intensities ranging from -4.7 to 1.9 log $\mathrm{cd}^{*} \mathrm{~s} / \mathrm{m}^{2}$ under scotopic and from -0.6 to $2.9 \mathrm{log} \mathrm{cd}^{*} \mathrm{~s} / \mathrm{m}^{2}$ under photopic conditions.

\subsection{RNA isolation, cDNA synthesis and semi-quantitative real-time PCR.}

Retinas were isolated through a slit in the cornea and immediately frozen in liquid nitrogen. Retinas were homogenized using a $21 \mathrm{G}$ needle and total RNA was prepared using the RNeasy RNA isolation kit (Qiagen, Hilden Germany) or the High Pure RNA isolation kit (Roche Diagnostics, Rotkreuz, Switzerland) including a DNase treatment to eliminate remaining genomic DNA. For reverse transcription, equal amounts of RNA were 
added to the reaction mix containing oligo(dT) primers and M-MLV reverse transcriptase (Promega, Madison, WI, USA). To study gene expression, $10 \mathrm{ng}$ of cDNA were mixed with specific primer pairs (Table 2) and SYBR Green I Master Mix (Roche Diagnostics), and reactions were run on a LighCycler 480 instrument (Roche Diagnostics). For relative quantification, gene expression was normalized to Actb and relative expression calculated using the comparative threshold method $\left(\Delta \Delta \mathrm{C}_{\mathrm{T}}\right)$.

\subsection{Laser capture microdissection (LCM).}

Unfixed enucleated eyes were embedded in RNase-free OCT tissue freezing medium (Leica Microsystems Nussloch $\mathrm{GmbH}$, Nussloch, Germany) and frozen in a 2-methylbutane bath cooled by liquid nitrogen. Sections of $20 \mu \mathrm{m}$ were cut on a cryostat (Leica Biosystems, Muttenz, Switzerland) and transferred to Arcturus PEN Membrane Glass Slides (Applied Biosystems, Foster City, CA, USA). For dehydration, sections were immersed in ice cold acetone for $5 \mathrm{~min}$ followed by air drying $(5 \mathrm{~min}$ ) and an ethanol bath for $30 \mathrm{~s}$ at room temperature. To increase contrast, the tissue was incubated in xylol for $5 \mathrm{~min}$ and air dried for $1 \mathrm{~h}$ at room temperature. The individual nuclear layers of the retina were separated using an Arcturus XT MDS system (Molecular devices, Silicon Valley, USA) based on a Nikon Eclipse Ti-E motorized microscope. Isolated layers were collected on CapSure Macro LCM Caps (Applied Biosystems). For RNA isolation, the PicoPure RNA isolation kit (Applied Biosystems) was applied including a DNase treatment and cDNA synthesis was performed using random hexamer primers (high-capacity cDNA reverse transcription kit, Applied Biosystems). To detect layer-specific gene expression, semi-quantitative real time PCR was accomplished as described above.

\subsection{Cell death detection ELISA (CDD ELISA).}

Cell death was quantified using the Cell Death Detection ELISA ${ }^{\text {PLUS }}$ kit (Roche Diagnostics) according to the manufacturer's instructions. Briefly, retinas were isolated through a slit in the cornea, frozen in liquid nitrogen and lysed in $400 \mu \mathrm{L}$ lysis buffer for 10 min at $21^{\circ} \mathrm{C}$ on a table top shaker (Eppendorf, Basel, Switzerland) set to 1'000 rpm. Samples were centrifuged at $200 \mathrm{~g}$ for $10 \mathrm{~min}, 20 \mu \mathrm{L}$ of the supernatant diluted 1:25 and free nucleosomes were detected by ELISA (absorbance at $405 \mathrm{~nm}$ ). Each sample was measured in duplicates and the mean was expressed relatively to a positive control provided by the kit. $20 \mu \mathrm{L}$ PBS served as negative control.

\subsection{RNA sequencing.}

Retinas were isolated through a slit in the cornea, immediately frozen in liquid nitrogen and stored at $-80{ }^{\circ} \mathrm{C}$. Total RNA was isolated as described above using the 
RNeasy RNA isolation kit. RNA purity were assessed using a nanodrop spectrophotometer (Thermo Scientific, Wilmington, DE, USA) and concentrations adjusted to $100 \mathrm{ng} / \mu \mathrm{L}$. Samples were further processed at the Functional Genomics Center Zurich (FGCZ, University of Zurich, Zurich, Switzerland) and sequencing was performed on an Illumina HiSeq instrument (Illumina, Eindhoven, The Netherlands) involving synthesis of a stranded RNA library with polyA selection of mRNA using the "Illumina TruSeq Stranded mRNA Sample Prep" kit. For clustering based on gene ontology, the two bioconductor packages edgeR (Robinson et al., 2010) and goseq (Young et al., 2010) were applied. Pathway analyses were performed using MetaCore (Thomson Reuters, New York, USA). 


\section{Results}

Protection of photoreceptors by hypoxic preconditioning is independent of Hif1a expression in rods (Thiersch et al., 2009). Since hypoxia does not only activate HIF1 but also HIF2 transcription factor, we tested whether inactivation of Hif2a might affect photoreceptor survival after light exposure in hypoxic preconditioned mice.

\subsection{Specific inactivation of Hif2a in photoreceptor cells.}

Mice containing two loxP sites that flank exon 2 of Epas1 (Gruber et al., 2007) were crossed with LMOPC1 mice that express CRE recombinase under control of the rhodopsin promoter (Opsin-Cre) (Le et al., 2006). CRE-mediated deletion of exon 2 that encodes the DNA binding bHLH domain leads to inactivation of HIF2A (Gruber et al., 2007). Opsin-Cre mice start to delete floxed sequences at around post natal day (PND) 7 with a very high specificity for rod photoreceptor cells (Le et al., 2006; Lange et al., 2011). However, since CRE expression is patchy in these mice (Lange et al., 2011) only 50 to $70 \%$ of rods lacked HIF2A.

Analyzing genomic DNA isolated from retinas of 10 -week old control mice (Hif2 $\left.a^{\text {floxflox }}\right)$ and of mice lacking HIF2A in a large number of rods (Rod ${ }^{\text {HHif2a }}$ ) showed that expression of CRE recombinase successfully deleted exon 2 (Fig. 1A). Note that genomic DNA was isolated from whole retinas and thus also contained DNA from cells not expressing CRE. Successful deletion resulted in a reduced expression of Hif2a mRNA whereas photoreceptor-specific marker genes such as rhodopsin (Rho), guanine nucleotide binding protein alpha (Gnat1) and Gnat2 were not affected (Fig. 1B). To verify that reduced expression of Hif2a was specific for the outer nuclear layer (ONL), we isolated the ONL, inner nuclear layer (INL) and the ganglion cell layer (GCL) by laser capture microdissection and analyzed expression of Hif2a in the three layers of control and Rod ${ }^{\text {Hif2a }}$ mice. Gnat1 (ONL), visual system homeobox 2 (Vsx2, INL) and POU class 4 homeobox 1 (Pou4f1, GCL) were amplified to assess the purity of the isolated layers. Data show that Hif2a was normally expressed in the INL and GCL, but was specifically reduced in the ONL.

\subsection{Rod-specific inactivation of HIF2A affects the transcriptome of hypoxic retinas}

Since HIF2A is the oxygen-regulated subunit of the HIF2 transcription factor, inactivation of Hif2a in rods should reduce expression of hypoxia inducible genes that are controlled by HIF2. To identify such genes, we exposed control (Hif2 $a^{\text {flox/flox }}$ ) and Rod ${ }^{\Delta H i f 2 a}$ mice to hypoxia during daylight (when photoreceptors have a reduced metabolic activity) and determined the retinal transcriptome by RNA sequencing. All mice used were controlled for Cre expression and the presence of the deletion fragment in genomic DNA isolated from the retina (data not shown). Although RNA was isolated from whole retinas 
containing a large number of cells not affected by CRE-mediated inactivation of Hif2a (Fig. $1)$, the heat map of significant transcripts $(P \leq 0.01$; $\log 2$ ratio $\geq 0.5)$ revealed a clear difference between the two mouse strains (Fig. 2A). We also noted variability between mice that was most evident in hypoxic Rod ${ }^{\Delta H i f 2 a}$ mice where one mouse showed an expression pattern that differed from the other two mice. The reason for this variability is unclear but may involve differences in Cre expression or a variable response to hypoxia in individual mice. As expected, most of the differentially regulated genes were downregulated in Rod ${ }^{\text {Hif2a }}$ mice (Table 3; suppl. Table 6) with perilipin 4 (PIn4) having the strongest reduction and a high significance. Not surprisingly, fold changes were generally low because the analyzed RNA originated from all cells of the retina with a large number of cells that still had functional Hif2a. The list of the top 30 downregulated genes revealed several candidates that were known to be regulated by hypoxia such as heat shock protein 1 (Hspb1) and placental growth factor (Pgf). Other interesting genes with slightly less strong fold-changes were identified in Hmox1, Cdkn1c, Timp3 and Htra1. Interestingly, Timp3 and Htra1 have been implicated in age-related macular degeneration (Vierkotten et al., 2011; Ardeljan et al., 2013). Fewer genes were found to be upregulated in hypoxic retinas of Rod ${ }^{\Delta H i f 2 a}$ mice, and these genes had generally a low fold-change of rather low significance (Table 4). Of note, expression of the HIF2 target gene Epo was not significantly affected by Hif2a knockdown in rods (Table 4) suggesting that rods are not major EPO producing cells. As expected, many genes of the ONL, INL, GCL and RPE did not show significant $P$-values along very low fold-changes and thus can be considered as controls for our experimental approach and methodology (Table 5). Differential expression of eight genes of interest was verified by real-time PCR using total retinal RNA from normoxic and hypoxic control and Rod $^{\text {AHif2a }}$ mice (Fig. 2B). Plin4 and Edn3 were chosen as the two genes downregulated the most in hypoxic Rod ${ }^{\Delta H i f 2 a}$ retinas. Lcn2 was investigated as an iron-binding protein that may participate in a number of cellular processes such as proliferation, differentiation and apoptosis (Ferreira et al., 2015), and as a protein that has been discussed as a potential biomarker for multiple sclerosis and age-dependent decline of cognitive functions (Ferreira et al., 2015). Although Hmox1, Cdkn1c, Timp3 and Htra1 had only low fold changes, they were analyzed because of their potential roles in retinal pathophysiology (Madhavan et al., 2010; Tong et al., 2010; Stöhr \& Anand-Apte, 2012; He et al., 2014). All of the tested genes were either significantly (PIn4, Lcn2, Htra1) induced or showed a tendency to be elevated after hypoxic exposure in control mice. All genes showed reduced expression in hypoxic $R_{0} d^{\text {Hif2a }}$ retinas, although only $C d k n 1 c$ and Htra1 reached significance. Since the RNA analyzed originated from rod cells affected by the deletion of Hif2a as well as from all other retinal cells, it is conceivable that significance would be reached if rods were specifically analyzed. The real-time PCR data showed that HIF2 influences hypoxic expression of a 
multitude of genes in rods and verified a successful inactivation of Hif2a in Rod ${ }^{\Delta H i f 2 a}$ mice. The hypoxic regulation of Pln4 was not reported before and its function in the retina warrants further evaluation.

\subsection{Rod-specific Hif2a inactivation does not affect retinal morphology and function.}

Lack of HIF2A in rods affected the gene expression pattern of hypoxic retinas (Fig. 2). Since photoreceptors experience borderline hypoxic conditions especially in darkness ( $\mathrm{Yu}$ \& Cringle, 2001; Caprara \& Grimm, 2012), we tested whether HIF2A in rods would be required for long-term survival and/or function of these cells. Data collected from 10 week and 1 year old mice revealed that lack of HIF2A in rods did not affect retinal morphology or function. All retinal layers, including the $\mathrm{ONL}$, were present and well organized in controls and $\operatorname{Rod}^{\Delta H i f 2 a}$ mice at both ages tested (Fig. 3A,B). Similarly, scotopic a- and b-wave as well as photopic b-wave amplitudes were not different between the strains at either age (Fig. $3 A, B)$, suggesting that lack of HIF2A in a large number of rods did not affect retinal tissue integrity or function.

\subsection{Rod-specific HIF2 is not essential for neuroprotection by hypoxic preconditioning.}

To test the influence of rod-specific HIF2 for photoreceptor protection by hypoxic preconditioning, control and Rod ${ }^{\Delta H i f 2 a}$ mice were exposed to $7 \%$ oxygen for 6 hours and exposed to 2 hours of $15^{\prime} 000$ lux of white light after 4 hours of reoxygenation and dark adaptation. Consequences of light exposure were tested by analyzing retinal morphology (Fig. 4A) and quantification of free nucleosomes as an indicator of apoptosis (Fig. 4B). Normoxic retinas of both genotypes were heavily damaged by light exposure as evidenced by the rupture and disintegration of the outer segments and the appearance of condensed chromatin (pyknotic) in most photoreceptor nuclei (Fig. 4A). In contrast, hypoxic preconditioned mice, irrespectively of the genotype, were strongly protected with outer segments largely intact and only few pyknotic photoreceptor nuclei detectable (black arrows, Fig. 4A), suggesting that rod-specific HIF2 activity is not required for hypoxiamediated protection of photoreceptors against light damage.

\subsection{Rod-specific HIF transcription factors are not essential for retinal morphology, function and neuroprotection by hypoxic preconditioning.}

Even though redundancy between HIF1 and HIF2 transcription factors appears to be limited (Jain et al., 1998; Warnecke et al., 2004), forced misbalanced expression of HIF1 and HIF2 alpha subunits may overcome target gene specificity (Warnecke et al., 2004). To address the possibility that HIF1 compensates for the lack of HIF2 in Rod ${ }^{\Delta H i f 2 a}$ mice, we 
generated mice that lacked both, HIF1A and HIF2A in rod photoreceptors. Characterization

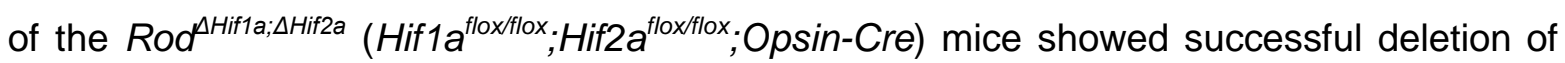
the floxed sequences in the retina on the genomic DNA level (Fig. 5A) and a normal retinal function at 11 weeks of age. Scotopic a-wave and b-wave as well as photopic b-wave amplitudes were similar in control (Hif1 $a^{\text {floxflox; }}$ Hif2 $a^{\text {flox/lox }}$ ) and Rod ${ }^{\Delta H i f 1 a ; \Delta H i f 2 a}$ mice (Fig. 5B). In addition, retinal morphology was also not affected by the lack of HIF1A and HIF2A transcription factors up to one year of age (Fig. $5 \mathrm{C}$ ).

When exposed to high levels of white light for 2 hours, strong retinal degeneration was detected in both mouse strains. Photoreceptor outer segments were largely disrupted and most nuclei appeared pyknotic at 36 hours after light exposure. After hypoxic preconditioning, however, both $\mathrm{Ctrl}$ and Rod ${ }^{\Delta H_{i f 1 a ;} \Delta \mathrm{Hif2a}}$ were protected against light damage with only few pyknotic photoreceptor nuclei detectable (Fig. 6A, black arrows). Morphologic data were confirmed by the quantification of cell death showing that both Ctrl and Rod $^{\Delta H_{i f 1 a ; \Delta H i f 2 a}}$ were strongly protected against light damage after hypoxic preconditioning (Fig. 6B). Although lack of both hypoxia-inducible transcription factors may increase light damage susceptibility in the normoxic retina, the two strains did not differ in their protection after hypoxic preconditioning (Fig. 6B). This suggests that neither HIF1 nor HIF2 is required in rods for protection against light damage by hypoxic preconditioning and implies that hypoxic exposure protects photoreceptors by an intrinsic pathway that is independent of HIF transcription factors or by a mechanism acting in trans. This may be supported by the analysis of gene expression of selected genes in normoxic and hypoxic Ctrl and Rod $^{\text {Hif1a; } \Delta H i f 2 a}$ retinas. Hypoxic expression of secreted factors that may affect cell survival such as Epo, adrenomedullin $(A d m)$, metallothionein-1 (Mt1) and Mt2 was induced in Rod $^{\text {Hif1a; } \Delta \text { Hif2a }}$ retinas (Fig. 6C). Thus, they may be produced in the inner retina or the RPE, reach the cells of the ONL and contribute to the protection of photoreceptors, even though e.g. Epo receptor $(E p o R)$ is not strongly expressed in the ONL (Caprara et al., 2014). 


\section{Discussion}

Hypoxic preconditioning efficiently protects photoreceptor cells against light-induced degeneration (Grimm et al., 2002). The mechanisms and factors behind the protection are not clear but primary candidates for contributing to the protection are the oxygen sensing HIF transcription factors. We recently showed, however, that survival of rods does not depend on intrinsic HIF1 activity (Thiersch et al., 2009). Here we tested HIF2 and showed that rods did also not need HIF2 for hypoxia-induced protection against light damage. Since even rod-specific Hif1a;Hif2a double knockout mice were protected, lack of HIF1 or of HIF2 was not compensated by the other factor. Thus, hypoxic preconditioning may either depend on other rod-derived factors, may be conferred in trans by the activity of other retinal cells or may be a consequence of systemic hypoxia.

\subsection{HIF1 and HIF2 in the retina.}

Genes for Hif1a and Hif2a are expressed in all layers of the adult mouse retina (Thiersch et al., 2009) (Fig. 1C). Upon hypoxic exposure, HIF1A protein has been detected throughout the retina including the ONL (Thiersch et al., 2009). Thus, several retinal cell types may activate the hypoxic response upon exposure to reduced oxygen levels.

Little is known about the expression pattern of HIF2A in the hypoxic retina, but stabilization has been reported in specific cells of the INL, presumably Müller glia cells, in a model of oxygen-induced retinopathy (Mowat et al., 2010). It is likely, however, that both HIF1A and HIF2A can be stabilized in most if not all retinal cell types as needed. Inactivation of $V h /$ in rod photoreceptor cells for example increased levels of both HIF1A and HIF2A proteins and expression of HIF target genes (Lange et al., 2011) suggesting that both HIF transcription factors can be activated in rods. In humans, basal levels of HIF1A protein have been detected in all nuclear layers of normal donor eyes (Hughes et al., 2010), and increased expression was observed in ganglion cells of glaucoma eyes (Tezel \& Wax, 2004; Reszeć et al., 2012), as well as in choroidal neovascular membranes (Sheridan et al., 2009).

Although both Hif1a and Hif2a are expressed in photoreceptors, rods did not depend on either of these genes for survival and function under normal conditions. Inactivation of Hif1a (Thiersch et al., 2009) or of Hif2a (Fig. 3) in rods did not affect retinal morphology or function suggesting that activity of these factors may only be needed in hypoxic situations. However, lack of one or both of these transcription factors did also not affect survival of rods after short-term hypoxic exposure (Figs. 4 and 6) (Thiersch et al., 2009). In fact, evidence suggests that inactivation of HIF1 may be rather beneficial for neuronal survival in the brain (Helton et al., 2005) and adult retina (Barben et al., manuscript in preparation). Thus, the potential function of HIF1 and HIF2 transcription factors in physiology and 
pathophysiology of rods is unclear and needs further evaluation. Clearly, however, HIF2 is functional in hypoxic rods since rod-specific inactivation of Hif2a changed the gene expression pattern (Fig. 2). A comparison between the retinal transcriptomes of hypoxic wild type and hypoxic Rod ${ }^{\Delta H i f 2 a}$ retinas revealed reduced expression of a number of genes (Fig. 2, Table 3, suppl Table 6) as it would be expected in the absence of a transcription factor. Since the transcriptomic analysis not only included rods that lacked HIF2 but all cells of the retina, it is not surprising that the reduction in expression levels was generally low.

\subsection{Photoreceptor protection by hypoxic preconditioning}

Our data shows that hypoxic preconditioning strongly protected rods lacking HIF transcription factors against light damage (this work and (Thiersch et al., 2009)). However, a small non-significant trend towards higher light damage susceptibility after hypoxic preconditioning was observed in mice lacking rod-specific HIF2 (Figs. 4 and 6). This may reflect the slight and transient protection of rods that have a hypoxia-like response activated through deletion of $V h l$ (Lange et al., 2011). Nevertheless, we conclude that the main protective response is not through activation of HIF1 or HIF2 in photoreceptors but may rely on one of three alternative mechanisms: i) intrinsic hypoxia-induced signaling cascades independent of HIF transcription factors activate a cell-autonomous protective response; ii) hypoxia-mediated activity of other retinal cells protect rods in a paracrine fashion - potential candidates include Müller glia cells, RPE and cones. Cones are of special interest since they are more sensitive to hypoxia than rods (Kurihara et al., 2012) and may thus react strongly to hypoxic preconditioning; iii) systemic effects caused by the hypoxic exposure of the mouse protect the cells in the retina. A recent study investigating the survival of retinal ganglion cells after hypoxic preconditioning in a model of glaucoma came to a very similar conclusion as it showed that intrinsic HIF1 is not required for ganglion cell protection (Zhu et al., 2013).

Few potential intrinsic mechanisms of hypoxic preconditioning that may not depend on HIF transcription factors have been suggested. Induction of a moderate ER stress for example may activate some components of the unfolded protein response (Li et al., 2011) potentially preparing photoreceptors to cope with acute light exposure. Alternatively, activation of p38 MAPK may be involved as it has been reported that hypoxic preconditioning induces p38 MAPK phosphorylation that leads to neuroprotection in a model of cerebral ischemic injury (Zhao et al., 2013). Finally, preconditioning may be protective through the regulation of cell volume by modulating $\mathrm{Cl}(-)$ and/or $\mathrm{K}(+)$ channels as it has been suggested for cardiomyocytes (Diaz et al., 2014).

Paracrine photoreceptor protection by hypoxic preconditioning may involve secreted factors produced by other cells. Apart from various cytokines and growth factors such as 
bFGF and EPO (Grimm et al., 2002), metallothioneins MT1 and MT2 are candidates for protection against light damage. Both genes were similarly induced in the hypoxic retina of control and Rod ${ }^{\Delta H i f 1 a ; \Delta H i f 2 a}$ double knockdown mice (Fig. 6) and are reported to be protective against oxidative stress (Chen et al., 2004; Suemori et al., 2006; Nachman-Clewner et al., 2008; Kim et al., 2012). Metallothioneins interact with various intracellular and extracellular factors involved in metal ion-related reactions (Atrian \& Capdevila, 2013) and may be of significance for ageing neuronal tissues (Sharma \& Ebadi, 2014). Interestingly, expression of Lrp2 that encodes the low-density lipoprotein receptor-related protein 2 (megalin) was slightly upregulated in Rod ${ }^{\text {AHif2a }}$ retinas (Table 4). LRP2 was reported to be the receptor for metallothioneins in brain tissue (Chung et al., 2008) and to be strongly expressed on photoreceptor segments (Wunderlich et al., 2010).

Another potential candidate molecule might be leptin. Leptin signaling has been proposed to be neuroprotective in addition to its role in the regulation of energy balance (Folch et al., 2012). Leptin has been suggested to confer protection by hypoxic preconditioned mesenchymal stem cells (Chen et al., 2014; Hu et al., 2014), and it has been reported that leptin expression and secretion is augmented by hypoxia (Wang et al., 2008). Interestingly, leptin has been discussed as a possible treatment for glaucoma (Gupta, 2013) and was shown to stimulate Müller glia cell reprogramming through JAK/STAT signaling in a model of retinal regeneration in zebrafish (Wang et al., 2008).

We conclude that photoreceptor protection by hypoxic preconditioning does not depend on activation of HIF transcription factors in rods. Furthermore, adult rod photoreceptors do also not depend on HIF1 and HIF2 under normal conditions as both transcription factors can safely be inactivated in adult rods without affecting retinal morphology or function. To use the neuroprotective potential of hypoxic preconditioning in therapeutic approaches, it is essential to identify the underlying molecular mechanisms. Identification of the signaling pathways involved may lead to the isolation of single molecules which may be applied to protect photoreceptors against degenerative insults.

\section{Acknowledgements}

We thank Jelena Kühn Georgijevic and Lennart Opitz from the functional genomics center Zurich (FGCZ) for RNA sequencing and their advice during evaluation of the transcriptomic data. Epas1-flox (Hif2a-flox) mice were generously provided by lan Frew, University of Zurich, Switzerland. Hif1a-flox mice were obtained from Max Gassmann, University of Zurich, Switzerland and Opsin-Cre mice were supplied by Yun Le, University of Oklahoma, USA. We thank Andrea Gruber and Coni Imsand for excellent technical 
assistance. This work was supported by the Swiss National Science Foundation (SNF, grant 31003A_149311) and the Robert and Rosa Pulfer Foundation, Switzerland. 


\section{References}

Ardeljan, D., Meyerle, C.B., Agron, E., Wang, J.J., Mitchell, P., Chew, E.Y., Zhao, J., Maminishkis, A., Chan, C.C.Tuo, J. 2013. Influence of TIMP3/SYN3 polymorphisms on the phenotypic presentation of age-related macular degeneration. Eur J Hum Genet 21: 1152-1157.

Arjamaa, O., Nikinmaa, M., Salminen, A.Kaarniranta, K. 2009. Regulatory role of HIF1alpha in the pathogenesis of age-related macular degeneration (AMD). Ageing Res Rev 8: 349-358.

Atrian, S.Capdevila, M. 2013. Metallothionein-protein interactions. Biomol Concepts 4: 143160.

Caprara, C., Britschgi, C., Samardzija, M.Grimm, C. 2014. The erythropoietin receptor is not required for the development, function, and aging of rods and cells in the retinal periphery. Mol Vis 20: 307-324.

Caprara, C.Grimm, C. 2012. From oxygen to erythropoietin: relevance of hypoxia for retinal development, health and disease. Prog Retin Eye Res 31: 89-119.

Chang, Z.Y., Yeh, M.K., Chiang, C.H., Chen, Y.H.Lu, D.W. 2013. Erythropoietin protects adult retinal ganglion cells against NMDA-, trophic factor withdrawal-, and TNF- $\alpha-$ induced damage. PLoS One 8: e55291.

Chen, L., Wu, W., Dentchev, T., Wong, R.Dunaief, J.L. 2004. Increased metallothionein in light damaged mouse retinas. Exp Eye Res 79: 287-293.

Chen, P., Wu, R., Zhu, W., Jiang, Z., Xu, Y., Chen, H., Zhang, Z., Chen, H., Zhang, L., Yu, H., Wang, J.Hu, X. 2014. Hypoxia preconditioned mesenchymal stem cells prevent cardiac fibroblast activation and collagen production via leptin. PLoS One 9: e103587.

Chung, R.S., Penkowa, M., Dittmann, J., King, C.E., Bartlett, C., Asmussen, J.W., Hidalgo, J., Carrasco, J., Leung, Y.K., Walker, A.K., Fung, S.J., Dunlop, S.A., Fitzgerald, M., Beazley, L.D., Chuah, M.I., Vickers, J.C.West, A.K. 2008. Redefining the role of metallothionein within the injured brain: extracellular metallothioneins play an important role in the astrocyte-neuron response to injury. J Biol Chem 283: 1534915358.

Colella, P., lodice, C., Di Vicino, U., Annunziata, I., Surace, E.M.Auricchio, A. 2011. Nonerythropoietic erythropoietin derivatives protect from light-induced and genetic photoreceptor degeneration. Hum Mol Genet 20: 2251-2262.

De Gooyer, T.E., Stevenson, K.A., Humphries, P., Simpson, D.A., Curtis, T.M., Gardiner, T.A.Stitt, A.W. 2006. Rod photoreceptor loss in Rho-/- mice reduces retinal hypoxia and hypoxia-regulated gene expression. Invest Ophthalmol Vis Sci 47: 5553-5560.

Diaz, R.J., Harvey, K., Boloorchi, A., Hossain, T., Hinek, A., Backx, P.H.Wilson, G.J. 2014. Enhanced cell volume regulation: a key mechanism in local and remote ischemic preconditioning. Am J Physiol Cell Physiol 306: C1191-9.

Ferreira, A.C., Dá Mesquita, S., Sousa, J.C., Correia-Neves, M., Sousa, N., Palha, J.A.Marques, F. 2015. From the periphery to the brain: Lipocalin-2, a friend or foe. Prog Neurobiol 131: 120-136.

Fletcher, E.L., Jobling, A.I., Vessey, K.A., Luu, C., Guymer, R.H.Baird, P.N. 2011. Animal models of retinal disease. Prog Mol Biol Transl Sci 100: 211-286.

Folch, J., Pedrós, I., Patraca, I., Sureda, F., Junyent, F., Beas-Zarate, C., Verdaguer, E., Pallàs, M., Auladell, C.Camins, A. 2012. Neuroprotective and anti-ageing role of leptin. J Mol Endocrinol 49: R149-56.

Greer, S.N., Metcalf, J.L., Wang, Y.Ohh, M. 2012. The updated biology of hypoxia-inducible factor. EMBO J 31: 2448-2460.

Grimm, C.Remé, C.E. 2013. Light damage as a model of retinal degeneration. Methods Mol Biol 935: 87-97.

Grimm, C., Wenzel, A., Groszer, M., Mayser, H., Seeliger, M., Samardzija, M., Bauer, C., Gassmann, M.Remé, C.E. 2002. HIF-1-induced erythropoietin in the hypoxic retina protects against light-induced retinal degeneration. Nat Med 8: 718-724.

Grimm, C., Wenzel, A., Stanescu, D., Samardzija, M., Hotop, S., Groszer, M., Naash, M., 
Gassmann, M.Remé, C. 2004. Constitutive overexpression of human erythropoietin protects the mouse retina against induced but not inherited retinal degeneration. $J$ Neurosci 24: 5651-5658.

Gruber, M., Hu, C.J., Johnson, R.S., Brown, E.J., Keith, B.Simon, M.C. 2007. Acute postnatal ablation of Hif-2alpha results in anemia. Proc Natl Acad Sci U S A 104: 2301-2306.

Gu, L., Xu, H., Wang, F., Xu, G., Sinha, D., Wang, J., Xu, J.Y., Tian, H., Gao, F., Li, W., Lu, L., Zhang, J.Xu, G.T. 2014. Erythropoietin exerts a neuroprotective function against glutamate neurotoxicity in experimental diabetic retina. Invest Ophthalmol Vis Sci 55: 8208-8222.

Gupta, A. 2013. Leptin as a neuroprotective agent in glaucoma. Med Hypotheses 81: 797802.

He, C., Zhao, C., Kumar, A., Lee, C., Chen, M., Huang, L., Wang, J., Ren, X., Jiang, Y., Chen, W., Wang, B., Gao, Z., Zhong, Z., Huang, Z., Zhang, F., Huang, B., Ding, H., Ju, R., Tang, Z., Liu, Y., Cao, Y., Li, X.Liu, X. 2014. Vasoprotective effect of PDGFCC mediated by HMOX1 rescues retinal degeneration. Proc Natl Acad Sci U S A 111: 14806-14811.

Helton, R., Cui, J., Scheel, J.R., Ellison, J.A., Ames, C., Gibson, C., Blouw, B., Ouyang, L., Dragatsis, I., Zeitlin, S., Johnson, R.S., Lipton, S.A.Barlow, C. 2005. Brain-specific knock-out of hypoxia-inducible factor-1alpha reduces rather than increases hypoxicischemic damage. J Neurosci 25: 4099-4107.

Hu, X., Wu, R., Jiang, Z., Wang, L., Chen, P., Zhang, L., Yang, L., Wu, Y., Chen, H., Chen, H., Xu, Y., Zhou, Y., Huang, X., Webster, K.A., Yu, H.Wang, J. 2014. Leptin signaling is required for augmented therapeutic properties of mesenchymal stem cells conferred by hypoxia preconditioning. Stem Cells 32: 2702-2713.

Hughes, J.M., Groot, A.J., Van Der Groep, P., Sersansie, R., Vooijs, M., Van Diest, P.J., Van Noorden, C.J., Schlingemann, R.O.Klaassen, I. 2010. Active HIF-1 in the normal human retina. J Histochem Cytochem 58: 247-254.

Jain, S., Maltepe, E., Lu, M.M., Simon, C.Bradfield, C.A. 1998. Expression of ARNT, ARNT2, HIF1 alpha, HIF2 alpha and Ah receptor mRNAs in the developing mouse. Mech Dev 73: 117-123.

Junk, A.K., Mammis, A., Savitz, S.I., Singh, M., Roth, S., Malhotra, S., Rosenbaum, P.S., Cerami, A., Brines, M.Rosenbaum, D.M. 2002. Erythropoietin administration protects retinal neurons from acute ischemia-reperfusion injury. Proc Natl Acad Sci U S A 99: 10659-10664.

Kent, D.L. 2014. Age-related macular degeneration: beyond anti-angiogenesis. Mol Vis 20: 46-55.

Kim, J.H., Nam, Y.P., Jeon, S.M., Han, H.S.Suk, K. 2012. Amyloid neurotoxicity is attenuated by metallothionein: dual mechanisms at work. J Neurochem 121: 751-762.

Kurihara, T., Westenskow, P.D., Bravo, S., Aguilar, E.Friedlander, M. 2012. Targeted deletion of Vegfa in adult mice induces vision loss. J Clin Invest 122: 4213-4217.

Lange, C., Heynen, S.R., Tanimoto, N., Thiersch, M., Le, Y.Z., Meneau, I., Seeliger, M.W., Samardzija, M., Caprara, C.Grimm, C. 2011. Normoxic activation of hypoxia-inducible factors in photoreceptors provides transient protection against light-induced retinal degeneration. Invest Ophthalmol Vis Sci 52: 5872-5880.

Le, Y.Z., Zheng, L., Zheng, W., Ash, J.D., Agbaga, M.P., Zhu, M.Anderson, R.E. 2006. Mouse opsin promoter-directed Cre recombinase expression in transgenic mice. Mol Vis 12: 389-398.

Li, J., Wang, J.J.Zhang, S.X. 2011. Preconditioning with endoplasmic reticulum stress mitigates retinal endothelial inflammation via activation of X-box binding protein 1. J Biol Chem 286: 4912-4921.

Loboda, A., Jozkowicz, A.Dulak, J. 2012. HIF-1 versus HIF-2--is one more important than the other. Vascul Pharmacol 56: 245-251.

Madhavan, J., Mallikarjuna, K., Vikas, K., George, R., Bremner, R.Kumaramanickavel, G. 2010. CDKN1C (p57KIP2) mRNA expression in human retinoblastomas. Ophthalmic 
Genet 31: 141-146.

Mowat, F.M., Luhmann, U.F., Smith, A.J., Lange, C., Duran, Y., Harten, S., Shukla, D., Maxwell, P.H., Ali, R.R.Bainbridge, J.W. 2010. HIF-1alpha and HIF-2alpha are differentially activated in distinct cell populations in retinal ischaemia. PLoS One 5: e11103.

Nachman-Clewner, M., Giblin, F.J., Dorey, C.K., Blanks, R.H., Dang, L., Dougherty, C.J.Blanks, J.C. 2008. Selective degeneration of central photoreceptors after hyperbaric oxygen in normal and metallothionein-knockout mice. Invest Ophthalmol Vis Sci 49: 3207-3215.

Okawa, H., Sampath, A.P., Laughlin, S.B.Fain, G.L. 2008. ATP consumption by mammalian rod photoreceptors in darkness and in light. Curr Biol 18: 1917-1921.

Peng, P.H., Huang, H.S., Lee, Y.J., Chen, Y.S.Ma, M.C. 2009. Novel role for the deltaopioid receptor in hypoxic preconditioning in rat retinas. $J$ Neurochem 108: 741-754.

Ratcliffe, P.J. 2013. Oxygen sensing and hypoxia signalling pathways in animals: the implications of physiology for cancer. J Physiol 591: 2027-2042.

Reszeć, J., Zalewska, R., Bernaczyk, P.Chyczewski, L. 2012. HIF-1 expression in retinal ganglion cells and optic nerve axons in glaucoma. Folia Histochem Cytobiol 50: 456459.

Rex, T.S., Wong, Y., Kodali, K.Merry, S. 2009. Neuroprotection of photoreceptors by direct delivery of erythropoietin to the retina of the retinal degeneration slow mouse. Exp Eye Res 89: 735-740.

Robinson, M.D., Mccarthy, D.J.Smyth, G.K. 2010. edgeR: a Bioconductor package for differential expression analysis of digital gene expression data. Bioinformatics 26: 139-140.

Ryan, H.E., Poloni, M., Mcnulty, W., Elson, D., Gassmann, M., Arbeit, J.M.Johnson, R.S. 2000. Hypoxia-inducible factor-1alpha is a positive factor in solid tumor growth. Cancer Res 60: 4010-4015.

Samardzija, M.Grimm, C. 2014. Mouse models for cone degeneration. Adv Exp Med Biol 801: 567-573.

SamardZiJa, M., S.C.F. Neuhauss, S. Joly, M. KuRZ-LeVInC. Grimm. 2010. Animal models for retinal degeneration(ed.) Animal Models for Retinal Diseases: 51-79. Springer.

Seeliger, M.W., Grimm, C., Ståhlberg, F., Friedburg, C., Jaissle, G., Zrenner, E., Guo, H., Remé, C.E., Humphries, P., Hofmann, F., Biel, M., Fariss, R.N., Redmond, T.M.Wenzel, A. 2001. New views on RPE65 deficiency: the rod system is the source of vision in a mouse model of Leber congenital amaurosis. Nat Genet 29: 70-74.

Sharma, S.Ebadi, M. 2014. Significance of metallothioneins in aging brain. Neurochem Int 65: 40-48.

Shen, W., Chung, S.H., Irhimeh, M.R., Li, S., Lee, S.R.Gillies, M.C. 2014. Systemic administration of erythropoietin inhibits retinopathy in RCS rats. PLoS One 9: e104759.

Sheridan, C.M., Pate, S., Hiscott, P., Wong, D., Pattwell, D.M.Kent, D. 2009. Expression of hypoxia-inducible factor-1alpha and -2alpha in human choroidal neovascular membranes. Graefes Arch Clin Exp Ophthalmol 247: 1361-1367.

Stöhr, H.Anand-Apte, B. 2012. A review and update on the molecular basis of pathogenesis of Sorsby fundus dystrophy. Adv Exp Med Biol 723: 261-267.

Suemori, S., Shimazawa, M., Kawase, K., Satoh, M., Nagase, H., Yamamoto, T.Hara, H. 2006. Metallothionein, an endogenous antioxidant, protects against retinal neuron damage in mice. Invest Ophthalmol Vis Sci 47: 3975-3982.

Tezel, G.Wax, M.B. 2004. Hypoxia-inducible factor 1alpha in the glaucomatous retina and optic nerve head. Arch Ophthalmol 122: 1348-1356.

Thiersch, M., Lange, C., Joly, S., Heynen, S., Le, Y.Z., Samardzija, M.Grimm, C. 2009. Retinal neuroprotection by hypoxic preconditioning is independent of hypoxiainducible factor-1 alpha expression in photoreceptors. Eur J Neurosci 29: 2291-2302.

Tong, Y., Liao, J., Zhang, Y., Zhou, J., Zhang, H.Mao, M. 2010. LOC387715/HTRA1 gene polymorphisms and susceptibility to age-related macular degeneration: A HuGE 
review and meta-analysis. Mol Vis 16: 1958-1981.

Vierkotten, S., Muether, P.S.Fauser, S. 2011. Overexpression of HTRA1 leads to ultrastructural changes in the elastic layer of Bruch's membrane via cleavage of extracellular matrix components. PLoS One 6: e22959.

Wang, B., Wood, I.S.Trayhurn, P. 2008. Hypoxia induces leptin gene expression and secretion in human preadipocytes: differential effects of hypoxia on adipokine expression by preadipocytes. J Endocrinol 198: 127-134.

Wang, Z.Y., Shen, L.J., Tu, L., Hu, D.N., Liu, G.Y., Zhou, Z.L., Lin, Y., Chen, L.H.Qu, J. 2009. Erythropoietin protects retinal pigment epithelial cells from oxidative damage. Free Radic Biol Med 46: 1032-1041.

Warnecke, C., Zaborowska, Z., Kurreck, J., Erdmann, V.A., Frei, U., Wiesener, M.Eckardt, K.U. 2004. Differentiating the functional role of hypoxia-inducible factor (HIF)-1alpha and HIF-2alpha (EPAS-1) by the use of RNA interference: erythropoietin is a HIF2alpha target gene in Hep3B and Kelly cells. FASEB J 18: 1462-1464.

Wenzel, A., Grimm, C., Samardzija, M.Remé, C.E. 2005. Molecular mechanisms of lightinduced photoreceptor apoptosis and neuroprotection for retinal degeneration. Prog Retin Eye Res 24: 275-306.

Wenzel, A., Reme, C.E., Williams, T.P., Hafezi, F.Grimm, C. 2001. The Rpe65 Leu450Met variation increases retinal resistance against light-induced degeneration by slowing rhodopsin regeneration. J Neurosci 21: 53-58.

Whitlock, N.A., Agarwal, N., Ma, J.X.Crosson, C.E. 2005. Hsp27 upregulation by HIF-1 signaling offers protection against retinal ischemia in rats. Invest Ophthalmol Vis Sci 46: $1092-1098$.

Wunderlich, K.A., Leveillard, T., Penkowa, M., Zrenner, E.Perez, M.T. 2010. Altered expression of metallothionein-I and $-\mathrm{II}$ and their receptor megalin in inherited photoreceptor degeneration. Invest Ophthalmol Vis Sci 51: 4809-4820.

Young, M.D., Wakefield, M.J., Smyth, G.K.Oshlack, A. 2010. Gene ontology analysis for RNA-seq: accounting for selection bias. Genome Biol 11: R14.

Yu, D.Y.Cringle, S.J. 2001. Oxygen distribution and consumption within the retina in vascularised and avascular retinas and in animal models of retinal disease. Prog Retin Eye Res 20: 175-208.

Zhao, J., Du, F., Shen, G., Zheng, F.Xu, B. 2015. The role of hypoxia-inducible factor-2 in digestive system cancers. Cell Death Dis 6: e1600.

Zhao, L., Liu, X., Liang, J., Han, S., Wang, Y., Yin, Y., Luo, Y.Li, J. 2013. Phosphorylation of p38 MAPK mediates hypoxic preconditioning-induced neuroprotection against cerebral ischemic injury via mitochondria translocation of $\mathrm{Bcl}-\mathrm{xL}$ in mice. Brain Res 1503: 78-88.

Zhu, Y., Zhang, L.Gidday, J.M. 2013. Role of hypoxia-inducible factor-1a in preconditioninginduced protection of retinal ganglion cells in glaucoma. Mol Vis 19: 2360-2372.

Zhu, Y., Zhang, Y., Ojwang, B.A., Brantley, M.A.Gidday, J.M. 2007. Long-term tolerance to retinal ischemia by repetitive hypoxic preconditioning: role of HIF-1alpha and heme oxygenase-1. Invest Ophthalmol Vis Sci 48: 1735-1743. 


\section{FIGURE LEGENDS}

Figure 1. Knockdown of Hif2a in the ONL. (A) Detection of unexcised (wt) and excised $(\Delta)$ Hif2a genomic fragments in retinas of two Hif2a $a^{f / f}$ and two Hif2a $a^{f / f}$ OOpsin-Cre mice as indicated. Bottom: schematic representation of exon 2 (E2) of Hif2a, the two loxP sites flanking E2 and the binding regions of the primers (arrows) used for PCR amplifications. (B) Expression levels of indicated genes in total retina of 11 -week old Hif2a ${ }^{f / f}$ control (CRE: -) and Hif2a ${ }^{f / f}$;Opsin-Cre (CRE: +) mice. Levels were normalized to Actb and expressed relatively to levels in controls that were set to 1 . Shown are means \pm SD of $N=3$. ${ }^{*}: P<$ 0.05 , t-test. Bottom: schematic representation of exon 1 (E1) and E2 of Hif2a, the two loxP sites and the binding regions of the primers (arrows) used for amplification of Hif2a by realtime PCR. (C) Expression levels of Hif2a in the outer nuclear layer (ONL), inner nuclear layer (INL) and ganglion cell layer (GCL) of 11-week old Hif2a ${ }^{f / f}$ (CRE: -) and Hif2a ${ }^{f / f}$;OpsinCre (CRE: + ) mice. Retinal layers were isolated by laser capture microdissection and gene expression analyzed by real-time PCR. Gnat1 (ONL), Vsx2 (INL) and Pou4f1 (GCL) have been amplified as controls for the purity of isolated layers. $N=3$. ${ }^{*}: P<0.05$, *: $P<0.01$, ttest.

Figure 2. Transcriptome of the hypoxic retina of control $\left(\mathrm{Ctrl} ; \mathrm{Hif2a}^{\mathrm{ft} / \mathrm{f}}\right)$ and Rod $\mathrm{d}^{\mathrm{HHif2a}}$ (Hif2a ${ }^{f / f}$;Opsin-Cre) mice. (A) Heat map of RNA sequencing data (significant transcripts) of Rod $^{\text {HHif2a }}$ and Ctrl mice at 12 weeks of age. Blue: reduced expression. Red: increased expression. Each column represents the expression pattern of one individual animal. $N=3$. (B) Expression levels of genes selected from the transcriptomic data in retinas of 11-week old normoxic and hypoxic Ctrl and Rod ${ }^{\Delta H i f 2 a}$ mice, as indicated. Expression levels were determined by real-time PCR, normalized to Actb and expressed relatively to levels in normoxic controls, which were set to 1 . Shown are means \pm SD of $N=5-9$ as indicated. *: $P$ $<0.05$. ${ }^{* *}: P<0.01$. ANOVA with Tukey's multiple comparison test.

Figure 3. Retinal morphology and function in mice lacking HIF2A in rods. Morphologies and function were determined at 10 weeks $(A)$ and 1 year $(B)$ of age. Shown are representative sections of the central retina of $C t r l$ and $R_{0} d^{\Delta H i f 2 a}$ mice. RPE: retinal pigment epithelium. ONL: outer nuclear layer. INL: inner nuclear layer. GCL: ganglion cell layer. $N=3-6$. Scale bar: $50 \mu \mathrm{m}$. Retinal function was determined by ERG and is presented as scotopic a-wave, scotopic b-wave and photopic b-wave amplitudes as a function of stimulus intensity. $N=3$ $\left(\operatorname{Rod}^{\Delta H i f 2 a}\right) . N=4\left(H_{i f 2 a^{f / /}}\right)$. 
Figure 4. Light damage susceptibility of $R_{0} d^{\Delta H i f 2 a}$ mice after hypoxic preconditioning. (A) Retinal morphologies of 11-week old control (Ctrl) and Rod ${ }^{\Delta H i f 2 a}$ mice were determined in dark control (dark) or light exposed (light) mice that were (hypoxic) or were not (normoxic) preconditioned by hypoxia. Retinas were prepared at 36 hours after light exposure. $N=3$ (Ctrl, all conditions); $N=3$ (Rod ${ }^{\Delta H i f 2 a}$, normoxic dark); $N=7$ (Rod ${ }^{\Delta H i f 2 a}$, normoxic light); $N=6$ (Rod ${ }^{\Delta H i f 2 a}$, hypoxic light); Black arrows point to pyknotic nuclei. Abbreviations as in figure 3. Scale bar: $50 \mu \mathrm{m}$. (B) Cell death was quantified in 11-week old light exposed (light) Ctrl (black bars) and Rod ${ }^{\text {AHif2a }}$ (blue bars) mice that were (hypoxic) or were not (normoxic) preconditioned by hypoxia. Shown are means \pm SD of $N=3$ (Ctrl, normoxic light), $N=3$ (Rod ${ }^{\Delta H i f 2 a}$, normoxic light); $N=10$ (Ctrl, hypoxic light); $N=10$ (Rod ${ }^{\text {Hif2a }}$, hypoxic light). ${ }^{* *}: P$ $<0.01 ;{ }^{* \star *}: P<0.001$. ns: not significant. ANOVA with Tukey's multiple comparison test. Only relevant comparisons are shown.

Figure 5. Retinal morphology and function in mice lacking HIF1A and HIF2A in rods. (A) Detection of unexcised (wt) and excised $(\Delta)$ Hif1a (top) and Hif2a (bottom) genomic fragments in retinas of two Hif1 $a^{f / f} ; H i f 2 a^{f / f}$ and two Hif1 $a^{t / f} ; H i f 2 a^{f / f} ;$ Opsin-Cre mice as indicated. (B) Retinal function of 11-week old control (Ctrl) and Hif1a ${ }^{\mathrm{t} / \text {; }}$;Hif2 ${ }^{\mathrm{t} / \mathrm{f}}$;Opsin-Cre (Rod $^{\text {Hif1a; } \triangle H \text { Hif2a }}$ ) mice was determined by ERG and is presented as scotopic a-wave, scotopic b-wave and photopic b-wave amplitudes as a function of stimulus intensity. $N=4$. (C) Retinal morphology of 10-week old and 1-year old Ctrl and Rod ${ }^{\Delta H i f 1 a ; \Delta H i f 2 a}$ mice. Shown are representative sections of the central retina of $N=4$ (10 weeks) and $N=1$ (1 year) mice. Abbreviations as in figure 3. Scale bar: $50 \mu \mathrm{m}$.

Figure 6. Light damage susceptibility of Rod ${ }^{\Delta H i f 1 a ; \Delta H i f 2 a}$ mice after hypoxic preconditioning. (A) Retinal morphologies of 11-week old control (Ctr) and Rod ${ }^{\Delta H i f 1 a ; \Delta H i f 2 a}$ mice were determined in dark control (dark) or light exposed (light) mice that were (hypoxic) or were not (normoxic) preconditioned by hypoxia. Retinas were prepared at 36 hours after light exposure. $N=4$ (Ctrl, normoxic dark), $N=4$ (Rod ${ }^{\Delta H i f 1 a ; \Delta H i f 2 a}$, normoxic dark); $N=3$ (Ctrl, normoxic light), $N=3$ (Rod ${ }^{\Delta H i f 1 a ; \Delta H i f 2 a}$, normoxic light); $N=4$ (Ctrl, hypoxic light); $N=3$ (Rod ${ }^{\text {Hifia;AHif2a }}$, hypoxic light). Black arrows point to pyknotic nuclei. RPE: retinal pigment epithelium; ONL: outer nuclear layer; INL: inner nuclear layer. Scale bar: $50 \mu \mathrm{m}$. (B) Cell death was quantified in 11-week old light exposed (light) Ctrl and Rod ${ }^{\Delta H i f 1 a ; \Delta H i f 2 a}$ mice that were (hyp) or were not (norm) preconditioned by hypoxia. Shown are means \pm SD of $N=3$ (Ctrl, normoxic light), $N=3$ (Rod ${ }^{\text {AHif1a;AHif2a }}$, normoxic light); $N=11$ (Ctrl, hypoxic light); $N=$ 10 (Rod $^{\text {AHif1a; } \Delta H i f 2 a}$, hypoxic light). $N=3$ (normoxic, light) and $N=10$ (hypoxic, light). (C) Expression levels of hypoxia-responsive genes in 11-week old normoxic and hypoxic Ctrl and Rod ${ }^{\Delta H i f 1 a ; \Delta H i f 2 a}$ mice, as indicated. Expression levels were normalized to Actb and 
expressed relatively to levels in normoxic controls, which were set to 1 . Shown are means \pm SD of $N=5$ (Ctrl, normoxic light), $N=5$ (Rod ${ }^{\Delta H i f 1 a ; \Delta H i f 2 a}$, normoxic light); $N=3$ (Ctrl, hypoxic light); $N=3$ (Rod ${ }^{\Delta H i f 1 a ; \Delta H i f 2 a}$, hypoxic light); as indicated. ${ }^{*}: P<0.05$. ${ }^{* *}: P<0.01$. ${ }^{* * *}: P<$ 0.0001 . ns: not significant. ANOVA with Tukey's multiple comparison test. Only relevant comparisons are shown.

Supplemental Table 6. Transcriptomic data showing differentially regulated genes in hypoxic Rod ${ }^{\text {Hif2a }}$ compared to hypoxic controls $\left(H i f 2 a^{\text {flox/flox }}\right)$ at 11 weeks of age. 


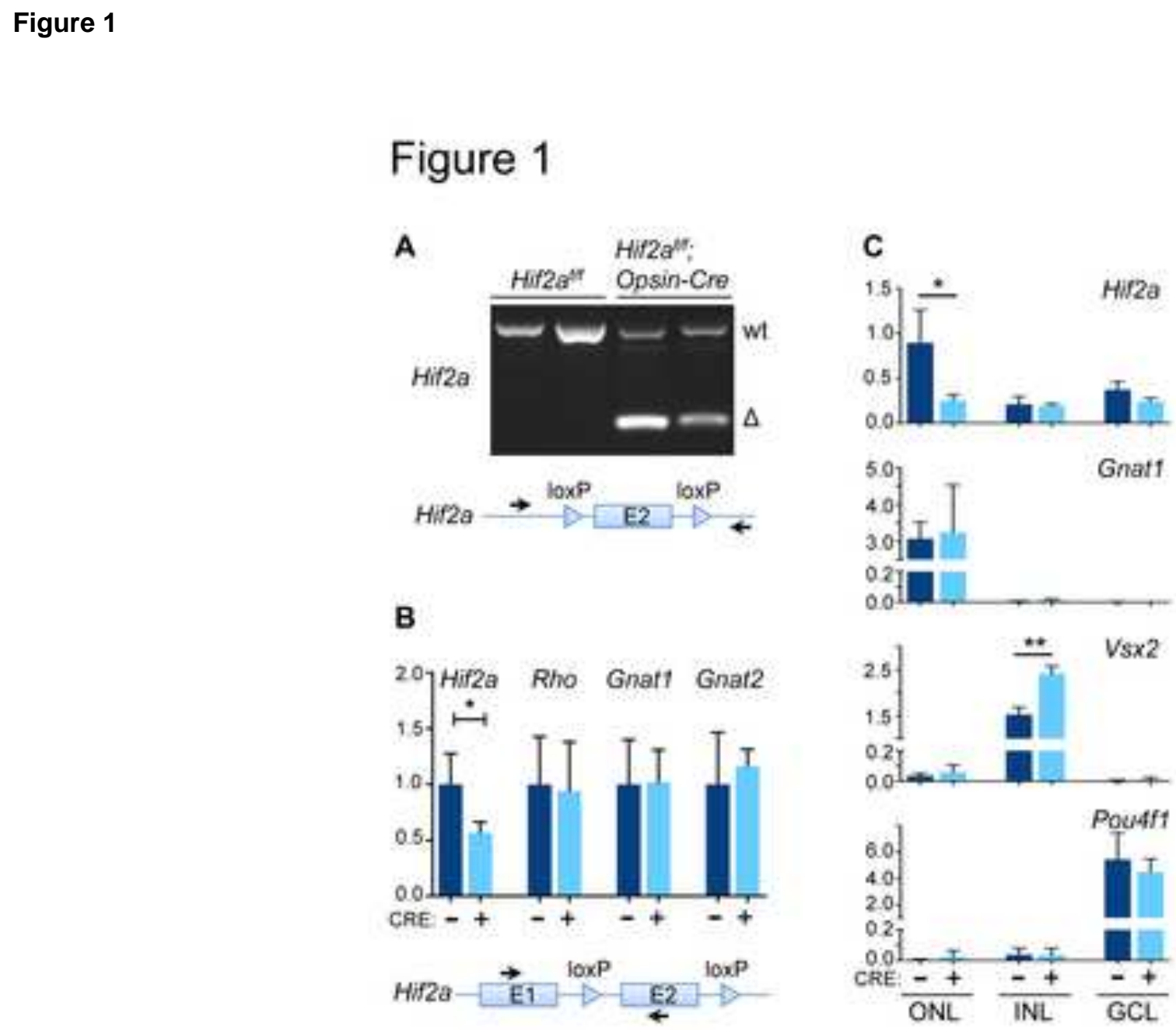

(1)

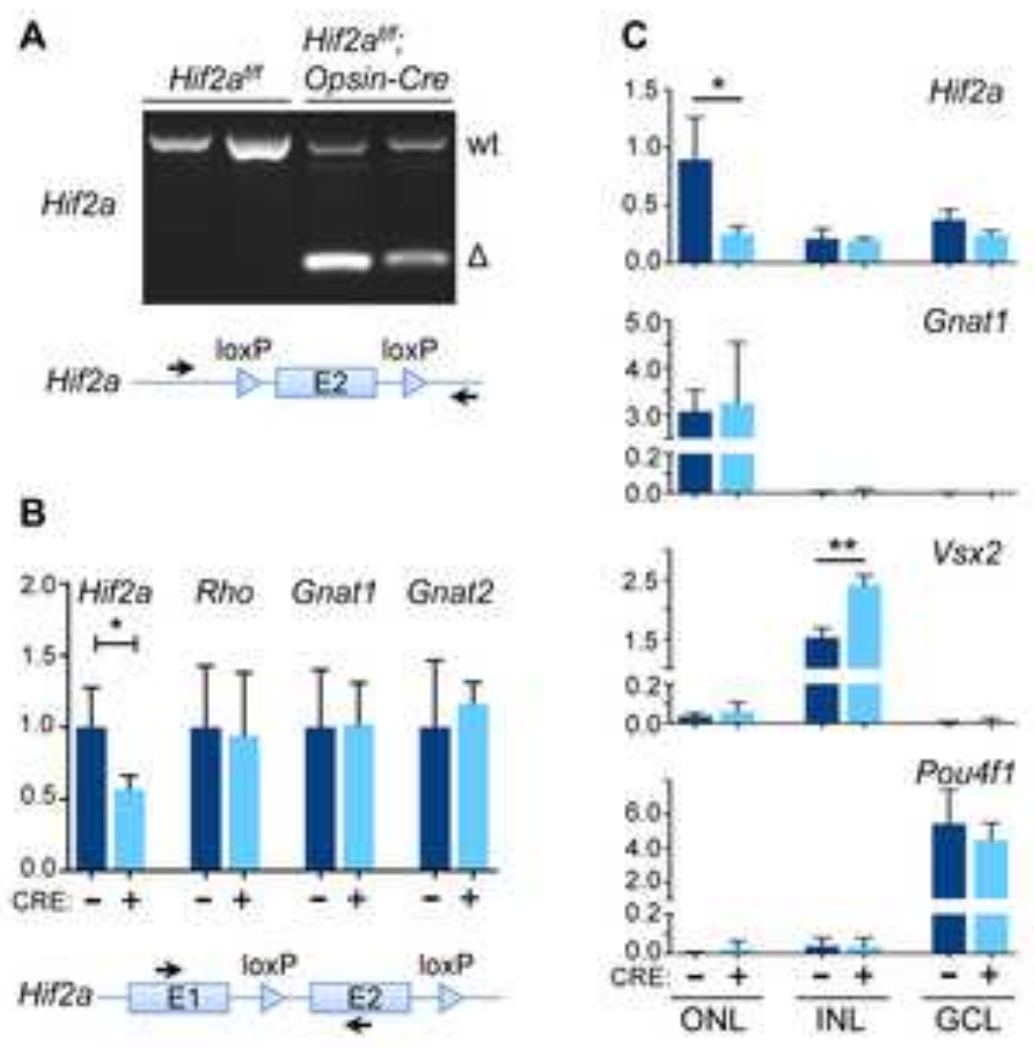

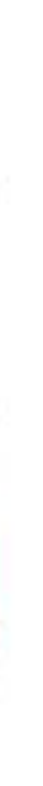

.

.

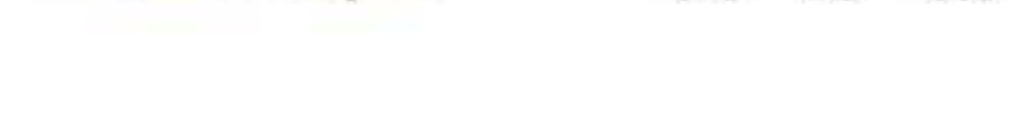


Figure 2

A

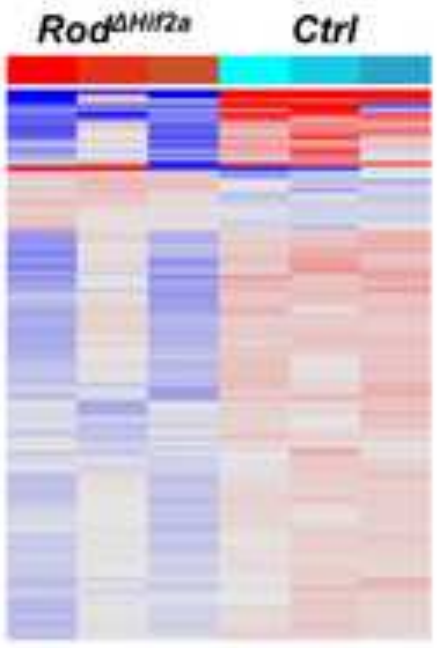

Significant transcripts
B

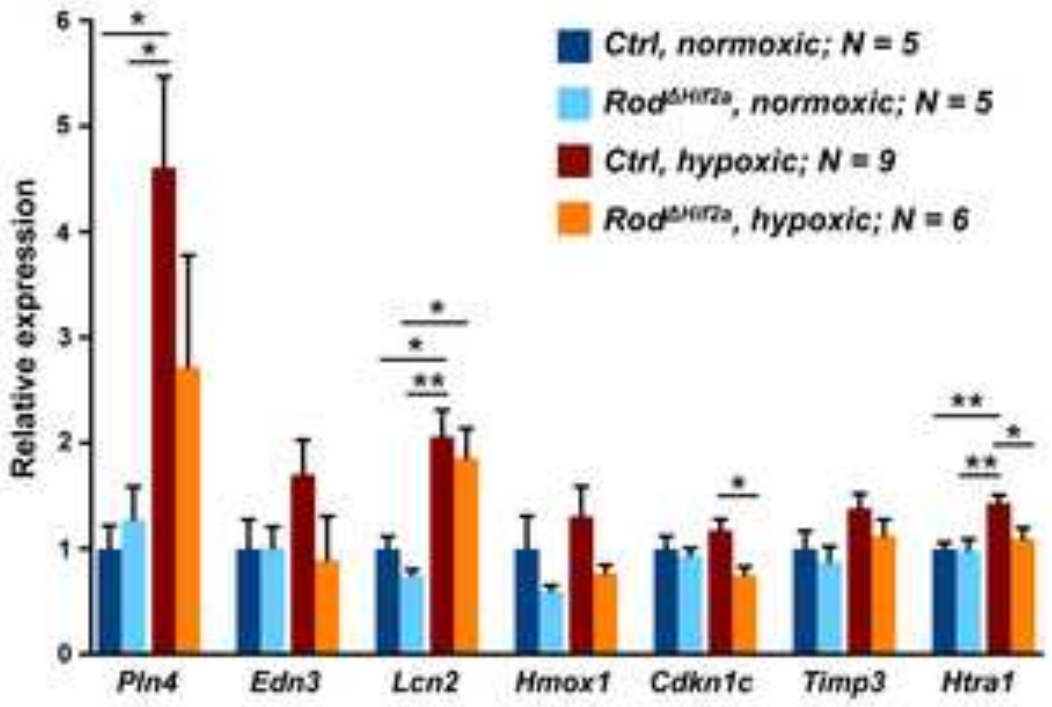


Figure 3

A

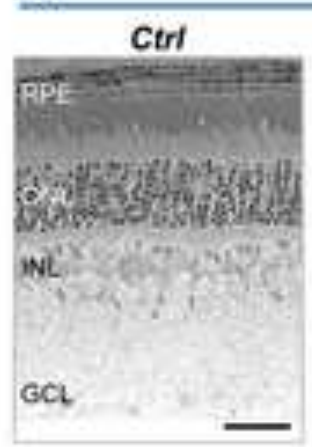

10 weeks

\section{Rodshira}

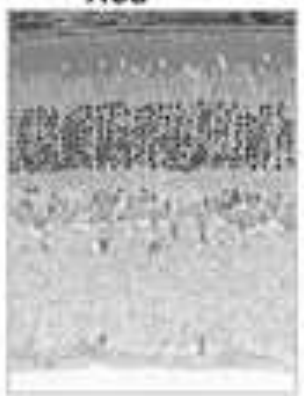

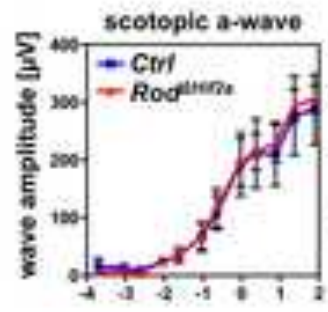
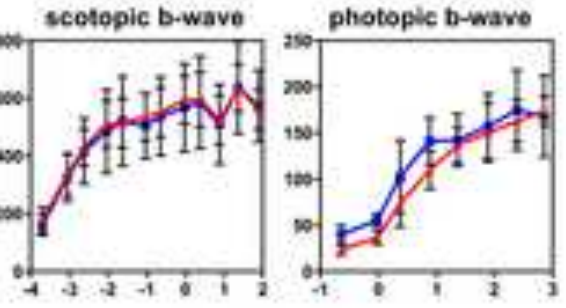

Stimulus intensity $\left[\log \left(\mathrm{cd} \times \mathrm{m} \mathrm{m}^{2}\right)\right]$
B

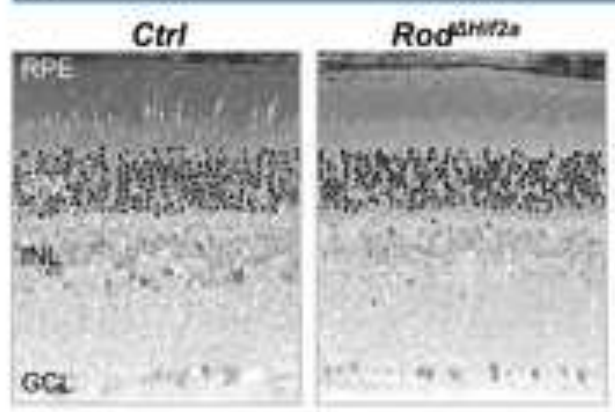

1 year
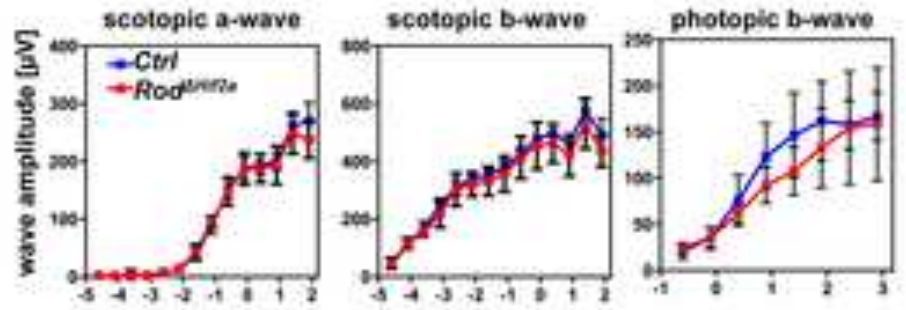

Stimulus intensity $\left[\log \left(c d x m^{2}\right)\right]$ 


\section{Figure 5}

A

Hif1 at: Hiffal:

Hif2a" Opsin-Cre

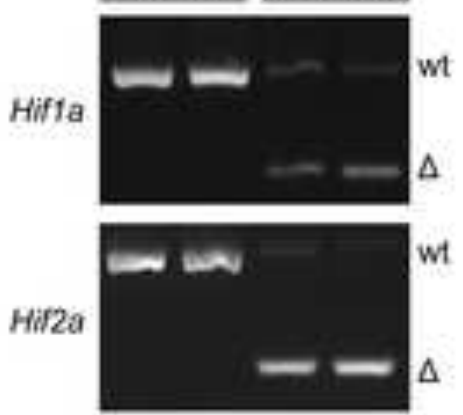

B
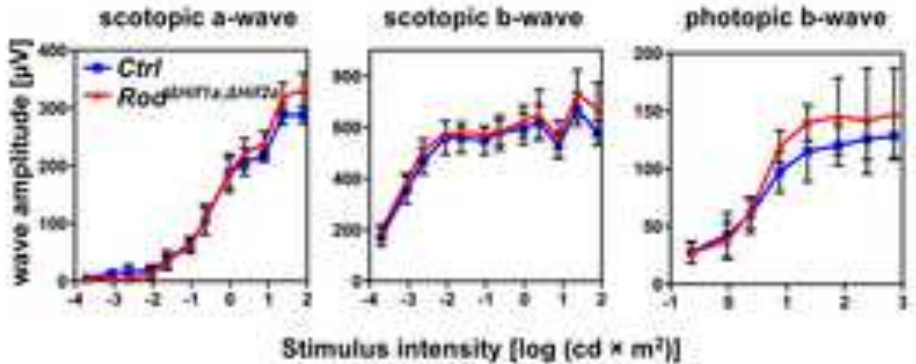

C

10 weeks

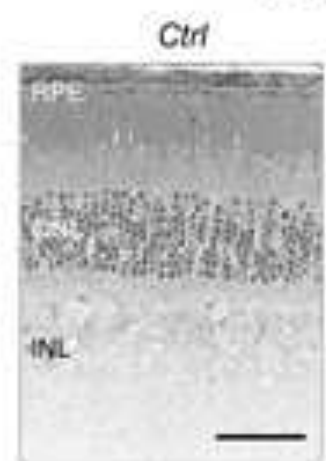

Rodewtadera

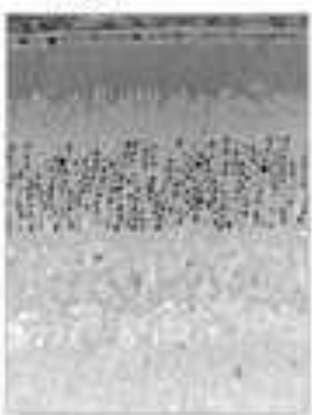

1 year

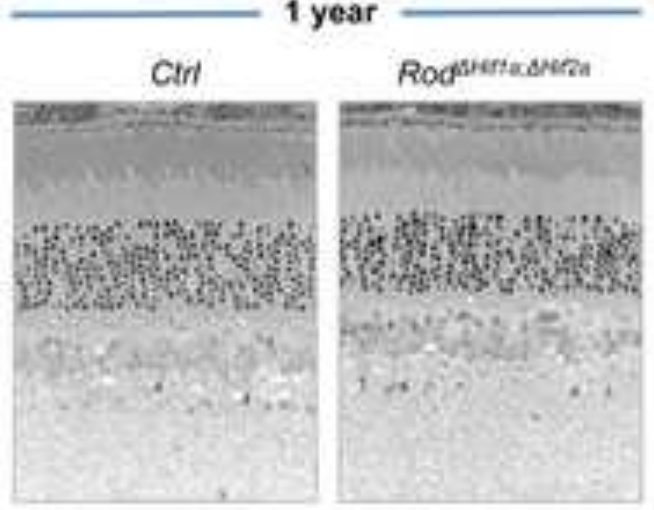


Figure 6
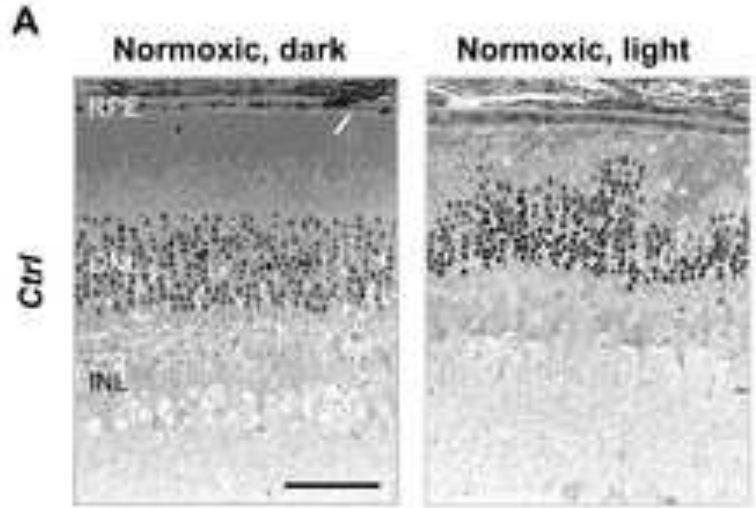

Hypoxic, light
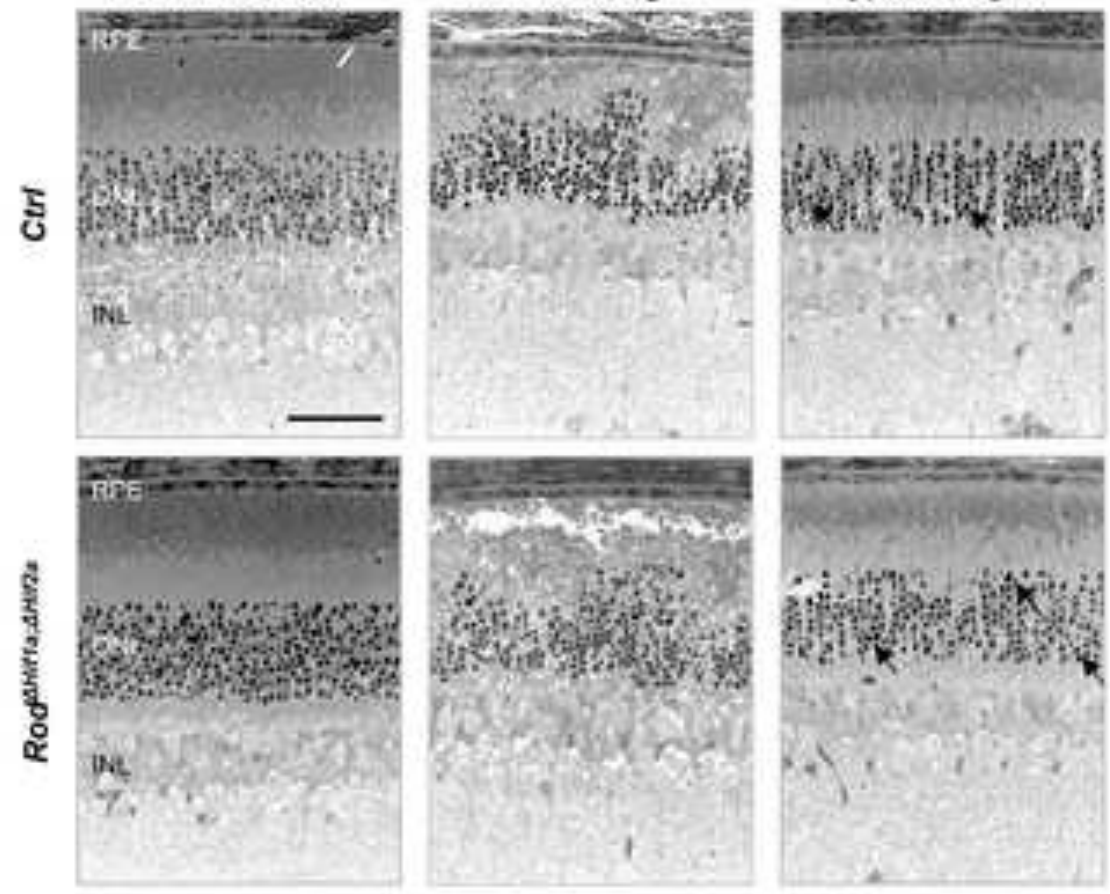

B
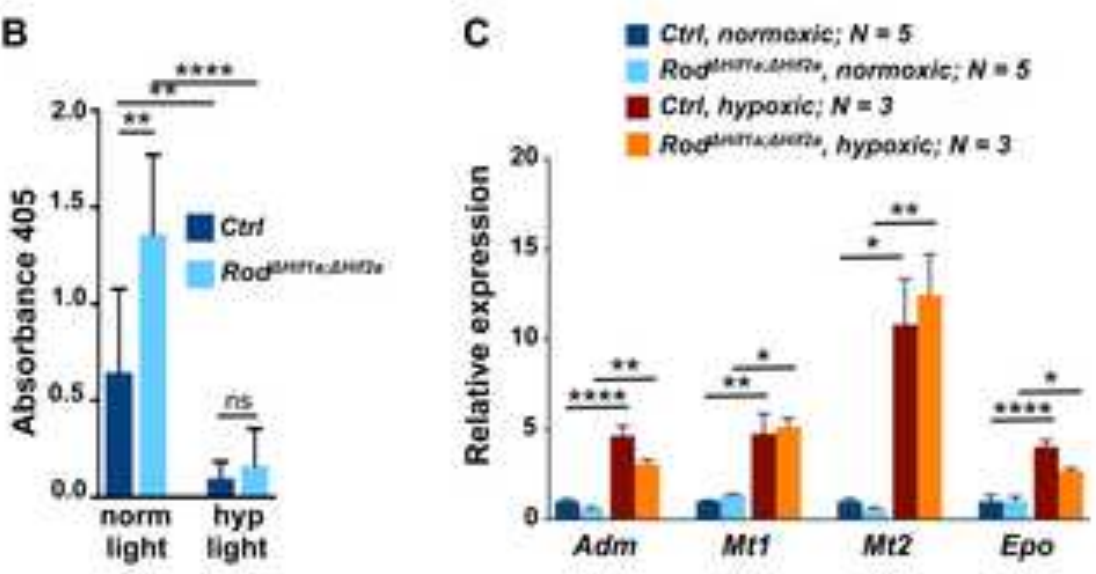
Table 1. Primers used for genotyping and detection of deletion fragments

\begin{tabular}{|c|c|c|}
\hline Gene & Primers 5' - 3' & Product [bp] \\
\hline$H i f 2 a^{t / f}$ & $\begin{array}{l}\text { forward: GAGAGCAGCTTCTCCTGGAA } \\
\text { reverse: TGTAGGCAAGGAAACCAAGG }\end{array}$ & $\begin{array}{l}182(w t) \\
220(2-l o x P)\end{array}$ \\
\hline OpsinCre & $\begin{array}{l}\text { forward: AGGTGTAGAGAAGGCACTTAGC } \\
\text { reverse: CTAATCGCCATCTTCCAGCAGG }\end{array}$ & 411 \\
\hline Hif1a & $\begin{array}{l}\text { forward: GCAGTTAAGAGCACTAGTTG } \\
\text { reverse: GGAGCTATCTCTCTAGACC }\end{array}$ & $\begin{array}{l}240(w t) \\
260(2-l o x P)\end{array}$ \\
\hline Hif2a deletion & $\begin{array}{l}\text { forward: CAGGCAGTATGCCTGGCTAATTCCAGTT } \\
\text { reverse: GCTAACACTGTACTGTCTGAAAGAGTAGC }\end{array}$ & $\begin{array}{l}1900(2-10 x P) \\
400(1-\text { loxP })\end{array}$ \\
\hline Hif1a deletion & $\begin{array}{l}\text { forward: TTGGGGATGAAAACATCTGC } \\
\text { reverse: GCAGTTAAGAGCACTAGTTG }\end{array}$ & $\begin{array}{l}1030(2-\text { loxP }) \\
280(1-\text { loxP })\end{array}$ \\
\hline
\end{tabular}


Table 2. Primers used for real-time PCR

\begin{tabular}{|c|c|c|c|}
\hline Gene & Forward 5' - 3' & Reverse 5' - 3' & $\begin{array}{r}\text { Product } \\
\text { [bp] }\end{array}$ \\
\hline Actb & CAACGGCTCCGGCATGTGC & CTCTTGCTCTGGGCCTCG & 153 \\
\hline Cdkn1c & GACGAGAATCAAGAGCAGCG & CACGTTTGGAGAGGGACACC & 183 \\
\hline Edn3 & ACGCACCAGAGATGTCACC & CCAGTCTCCCGCATCTCTT & 72 \\
\hline Gnat1 & GAGGATGCTGAGAAGGATGC & TGAATGTTGAGCGTGGTCAT & 209 \\
\hline Gnat2 & GCATCAGTGCTGAGGACAAA & CTAGGCACTCTTCGGGTGAG & 192 \\
\hline Hmox1 & CCGCCTTCCTGCTCAACATT & GACGAAGTGACGCCATCTGTG & 99 \\
\hline Htra1 & TAGCGACGCCAAGACCTACA & TCTTCTCСACСACATCAGCA & 176 \\
\hline Hif2a & GGGTTAAGGAACCCAGGTG & ATGGAGGCTTTGTCCAGGT & 213 \\
\hline Lcn2 & TGTACAGCACCATCTATGAGC & TGTTCTGATCCAGTAGCGAC & 101 \\
\hline Plin4 & CAGCACAACCAGTTCCAAGC & CCGCATCTCATGGCTACCAA & 153 \\
\hline Pou4f1 & CGCCGCTGCAGAGCAACCTCTT & TGGTACGTGGCGTCCGGCTT & 130 \\
\hline Rho & CTTCACCTGGATCATGGCGTT & TTCGTTGTTGACCTCAGGCTTG & 130 \\
\hline Timp3 & GCCTCAAGCTAGAAGTCAACAAA & TGTACATCTTGCCTTCATACACG & 69 \\
\hline Vsx2 & CCAGAAGACAGGATACAGGTG & GGCTCCATAGAGACCATACT & 111 \\
\hline
\end{tabular}


Table 3. Top down regulated genes $(P<0.005)$, and genes tested by real-time PCR (bold)

\begin{tabular}{|c|c|c|c|}
\hline Gene & Description & p-Value & $\begin{array}{l}\text { Fold } \\
\text { change }\end{array}$ \\
\hline Plin4 & perilipin 4 & $9.38 \mathrm{E}-19$ & -3.39 \\
\hline Edn3 & endothelin 3 & $1.28 \mathrm{E}-05$ & -2.74 \\
\hline Gpr160 & G protein-coupled receptor 160 & 0.0003585 & -2.71 \\
\hline Snx22 & sorting nexin 22 & $3.78 \mathrm{E}-05$ & -2.65 \\
\hline Slc10a6 & solute carrier family 10 , member 6 & 0.001648 & -2.62 \\
\hline Lenep & lens epithelial protein & 0.002221 & -2.54 \\
\hline Hspb1 1 & heat shock protein 1 & 0.002857 & -2.50 \\
\hline Cryga & crystallin, gamma A & 0.00213 & -2.49 \\
\hline Smco3 & single-pass membrane protein with coiled-coil domains 3 & 0.0002378 & -2.49 \\
\hline Pgam2 & phosphoglycerate mutase 2 & 0.0004205 & -2.46 \\
\hline Cela1 & chymotrypsin-like elastase family, member 1 & 7.30E-05 & -2.44 \\
\hline Chrng & cholinergic receptor, nicotinic, gamma polypeptide & 0.002825 & -2.43 \\
\hline Ces5a & carboxylesterase $5 \mathrm{~A}$ & 0.003031 & -2.42 \\
\hline Pgf & placental growth factor & 0.0002469 & -2.40 \\
\hline Edaradd & EDAR (ectodysplasin-A receptor)-associated death domain & 0.003513 & -2.40 \\
\hline Lcn2 & lipocalin 2 & $3.09 \mathrm{E}-10$ & -2.30 \\
\hline Fas & Fas (TNF receptor superfamily member 6 ) & 0.0008604 & -2.20 \\
\hline Metrnl & meteorin, glial cell differentiation regulator-like & 0.001699 & -2.16 \\
\hline Mgmt & O-6-methylguanine-DNA methyltransferase & 0.004146 & -2.15 \\
\hline Gpd1 & glycerol-3-phosphate dehydrogenase 1 (soluble) & 4.40E-06 & -2.13 \\
\hline Hebp2 & heme binding protein 2 & 0.00041 & -2.12 \\
\hline Pik3cg & phosphoinositide-3-kinase, catalytic, gamma polypeptide & 0.002502 & -2.11 \\
\hline lyd & iodotyrosine deiodinase & 0.004863 & -2.11 \\
\hline Plp2 & proteolipid protein 2 & 0.002001 & -2.03 \\
\hline Epha2 & Eph receptor A2 & 4.85E-05 & -1.97 \\
\hline Pdlim1 & PDZ and LIM domain 1 (elfin) & 0.0002497 & -1.94 \\
\hline Pmel & premelanosome protein & 0.0004545 & -1.93 \\
\hline Spsb1 & splA/ryanodine receptor domain and SOCS box containing 1 & $7.48 \mathrm{E}-05$ & -1.92 \\
\hline Tst & thiosulfate sulfurtransferase, mitochondrial & 0.0004366 & -1.92 \\
\hline Hmox1 & heme oxygenase (decycling) 1 & 0.0009687 & -1.81 \\
\hline Cdkn1c & cyclin-dependent kinase inhibitor 1C (P57) & $2.58 \mathrm{E}-07$ & -1.66 \\
\hline Timp3 & tissue inhibitor of metalloproteinase 3 & $7.00 \mathrm{E}-08$ & -1.53 \\
\hline Htra1 & HtrA serine peptidase 1 & $2.28 \mathrm{E}-05$ & -1.33 \\
\hline
\end{tabular}


Table 4. Top up regulated genes $(P<0.005)$

\begin{tabular}{lllr}
\hline Gene & Description & p-Value & $\begin{array}{l}\text { Fold } \\
\text { change }\end{array}$ \\
\hline Oasl2 & 2'-5' oligoadenylate synthetase-like 2 & 0.0002773 & 1.95 \\
Pla2g4e & phospholipase A2, group IVE & 0.0001783 & 1.69 \\
Antxr2 & anthrax toxin receptor 2 & 0.001118 & 1.61 \\
Samd11 & sterile alpha motif domain containing 11 & 0.000831 & 1.56 \\
Wdr66 & WD repeat domain 66 & $7.05 \mathrm{E}-05$ & 1.50 \\
Plekhn1 & pleckstrin homology domain containing, family N member 1 & $7.19 \mathrm{E}-05$ & 1.46 \\
Hfm1 & HFM1, ATP-dependent DNA helicase homolog (S. cerevisiae) & 0.00376 & 1.43 \\
Slc30a2 & solute carrier family 30 (zinc transporter), member 2 & 0.0005512 & 1.38 \\
Cyp1b1 & cytochrome P450, family 1, subfamily b, polypeptide 1 & 0.003877 & 1.38 \\
Lrp2 & low density lipoprotein receptor-related protein 2 & 0.004138 & 1.38 \\
Dnah7b & dynein, axonemal, heavy chain 7B & 0.0003496 & 1.33 \\
Garem & GRB2 associated, regulator of MAPK1 & $3.23 \mathrm{E}-05$ & 1.32 \\
Igsf21 & immunoglobulin superfamily, member 21 & $1.99 \mathrm{E}-05$ & 1.31 \\
Cav1 & caveolin 1, caveolae protein & 0.002393 & 1.28 \\
Cd276 & CD276 antigen & 0.00391 & 1.26 \\
Camk4 & calcium/calmodulin-dependent protein kinase IV & 0.002549 & 1.24 \\
Ago3 & argonaute RISC catalytic subunit 3 & 0.001787 & 1.22 \\
Kdr & kinase insert domain protein receptor & 0.003734 & 1.21 \\
Ttbk2 & tau tubulin kinase 2 & 0.003122 & 1.21 \\
Cdk19 & cyclin-dependent kinase 19 & 0.002247 & 1.18 \\
Abca8a & ATP-binding cassette, sub-family A (ABC1), member 8a & 0.003744 & 1.17 \\
Npc1 & Niemann Pick type C1 & 0.002289 & 1.15 \\
& & & \\
Epo & erythropoietin & 0.4865 & 1.23 \\
\hline
\end{tabular}


Table 5. Control genes

\begin{tabular}{lllr}
\hline Gene & Description & p-Value & $\begin{array}{r}\text { Fold } \\
\text { change }\end{array}$ \\
\hline Rho & rhodopsin & 0.5292 & -1.03 \\
Opn1mw & opsin 1 (cone pigments), medium-wave-sensitive & 0.231 & -1.06 \\
Opn1sw & opsin 1 (cone pigments), short-wave-sensitive & 0.8597 & -1.01 \\
Gnat1 & guanine nucleotide binding protein, alpha transducing 1 & 0.4516 & -1.03 \\
Gnat2 & guanine nucleotide binding protein, alpha transducing 2 & 0.5174 & -1.04 \\
Opn4 & opsin 4 (melanopsin) & 0.5493 & -1.09 \\
Vsx2 & visual system homeobox 2 & 0.2906 & 1.06 \\
Pou4f1 & POU domain, class 4, transcription factor 1 & 0.767 & 1.04 \\
Rpe65 & retinal pigment epithelium 65 & 0.3416 & 1.24 \\
Actb & actin, beta & 0.2956 & -1.06 \\
\hline
\end{tabular}

